\title{
CONSIDERAÇÕES SOBRE FAZER E VIVER DE ARTE EM TEMPOS SOMBRIOS
}

\section{CONSIDERATIONS ON MAKING ART AND MAKING A LIVING OF IT IN DARK TIMES}

\author{
Leonardo Balbino Mascarenhas \\ leo.mascarenhas@gmail.com
}

UFMG

\begin{abstract}
Resumo:
Como podemos construir, no mundo contemporâneo, a prática e a sobrevivência de artistas no mundo do trabalho? Como se profissionalizar e "viver da arte"? Quais as possibilidades de realização de uma produção artística que não se dê de modo frágil e precário, apoiada quase que exclusivamente na força de vontade e insistência dos artistas? Como superar os contextos de escassez e fazer arte em condições de abundância (econômica, democrática, estética, política, ética...)? O presente artigo buscar refletir sobre estas questões. E, mais do que tentar respondêlas de forma precisa e definitiva, busca-se neste trabalho analisar os processos sociais que atuam tentando restringir nossos modos de existência, assim como refletir sobre as possibilidades de resistência e de invenção ética, estética e política. Pois é preciso, mais do que nunca, que façamos novas apropriações, conexões, relações e atravessamentos, que arejem nosso pensamento e nossas formas de relação com o mundo.
\end{abstract}

Palavras-chave: Arte contemporânea, profissionalização artística, teatro e resistência.

\begin{abstract}
:
How can we build, in the contemporary world, the practice and survival of artists in the world of work? How to professionalize and make a living as an artist? What are the possibilities for the realization of an artistic production that is not fragile and precarious, based almost exclusively on the will and insistence of the artists? How to overcome the contexts of scarcity and make art in conditions of abundance (economic, democratic, aesthetic, political, ethical ...)? This article seeks to reflect on these issues. And, rather than trying to answer them precisely and definitively, this paper seeks to analyze the social processes that work by trying to restrict our modes of existence, as well as to reflect on the possibilities of resistance and of an ethical, aesthetic and political invention. Because it is necessary, more than ever, that we make new appropriations, connections, relations and crossings, that air our way of thinking and our forms of relation with the world.
\end{abstract}

Keywords: Contemporary art, artistic professionalization, theater and resistance.

\section{Primeiro Ato: situar-se (cenários; figurinos \& roteiros)}

Nas últimas décadas, o mundo do trabalho passou por profundas modificações, resultado de uma série de fatores, dentre os quais podemos destacar: 1) a emergência de uma sociedade 
pós-industrial, a partir dos anos 1970, que suplantou o modelo de trabalho fordista ${ }^{1}$, em favor de formas mais flexíveis de produção, de organização do trabalho e do trabalhador, e orientando-se não mais pela centralidade das disciplinas, mas pelo controle difuso ${ }^{2} ; 2$ ) as ondas globalizantes e neoliberais, cujas expressões mais significativas foram o Consenso de Washington, nos anos 1980, e o neoliberalismo crescente dos anos 2000 em diante, e que caracterizam-se pela financeirização da economia, enfraquecimento dos Estados nacionais e dos blocos econômicos locais, intensificação no fluxo de capitais dos países periféricos para os centrais, abertura das economias dos países periféricos e irrestrito controle das mesmas, via ajustamento fiscal e controle do endividamento $^{3}$; 3) o enfraquecimento das organizações sindicais e a diluição do conflito capitaltrabalho, cujo resultado é a perda de consciência de classe e piores condições de negociação com o patronato; 4) a ocidentalização dos modos de existência capitalísticos, baseados no consumo exacerbado, na medicalização e judicialização da vida, e com a respectiva marginalização e perseguição dos modos alternativos de existência; 5) a continuidade e ampliação das formas de opressão e controle social baseados no patriarcado e no colonialismo (inclusive, do ponto de vista epistemológico, o que justifica muitos cientistas sociais falarem atualmente num epistemicídio, ao analisarem a produção social das sociedades periféricas) ${ }^{4}$; 6) a ascensão mundial de uma ideologia de extrema direita, abertamente machista, homofóbica, racista, xenófoba e classista ${ }^{5}$.

Todos esses acontecimentos influenciam enormemente os modos de se viver (e sobreviver), em todas as partes do mundo. No Brasil, especificamente, os últimos anos tem sido de intensa agitação e crise nos campos político e econômico: atravessamos um agravamento da crise econômica desde 2014, da qual ainda não nos recuperamos ${ }^{6}$; sofremos um golpe em 2016,

10 modo fordista de produção foi hegemônico na primeira metade do século XX e baseava-se no amplo uso do disciplinamento dos corpos (no sentido de adestrá-lo para o trabalho fabril, e extrair dele os melhores resultados em termos de tempo e movimento), na concentração da força de trabalho e na produção em massa (conforme FOUCAULT, 2003).

2 A este respeito, ver as considerações deleuzianas sobre as sociedades de controle, disponíveis no post-scriptum de Deleuze, 1992.

3 Para uma análise mais detalhada, ver Santos, 2002.

4 Ver, por exemplo, o trabalho de Santos e Meneses (2010).

5 Note-se que apesar de aparentarem ser os maiores expoentes desse movimento, os governos Trump e Bolsonaro são apenas uma parte dele; há, atualmente, por toda parte, lideranças com ideias semelhantes, guardadas as devidas diferenças culturais e históricas: Marine Le Pen, na França; Viktor Orbán, na Hungria; Matteo Salvini, na Itália; Vladimir Putin, na Rússia; Sebastian Kurz, na Áustria; Boris Johnson, no Reino Unido; os membros do Vox, partido de extrema direita espanhol; entre outros.

6 Apesar da crise financeira internacional de 2008 ter sido sentida no Brasil mais fortemente a partir de 2011, ainda no primeiro mandato de Dilma Rousseff, foi em 2014 que as condições políticas e econômicas se agravaram, como resultado de uma conjunção de fatores, dentre os quais podemos destacar: contenção do gasto público, declínio da 
com a derrubada de uma presidenta eleita democraticamente e destituída do cargo por um conluio dos poderes mais conservadores, aristocráticos, oligárquicos e antidemocráticos existente no país ${ }^{7}$; elegemos, no fim de 2018, um executivo federal e uma maioria legislativa que praticam abertamente a violência e a boçalidade, são explicita e despudoradamente antidemocráticos, e celebram a perseguição às minorias, o fortalecimento das instituições militares e paramilitares, o sucateamento da educação, da cultura e das políticas sociais, a disseminação de mentiras como estratégia de governo, o ataque à preservação do meio ambiente e aos povos indígenas, e que se alinham a uma política econômica neoliberal de financeirização da economia, redução do Estado de bem estar social a um Estado mínimo, dentre tantas outras atrocidades.

No campo das artes especificamente, isso tem se traduzido na eliminação de oportunidades de trabalho (via sucateamento dos aparelhos de Estado e das políticas públicas na área da cultura), e na precarização ainda maior dos profissionais das artes (resultado da ampliação da ideologia do empreendedorismo, da falta de valorização do artista, da existência de poucos e restritos mercados, localizados basicamente no eixo Rio-São Paulo, e da recorrente falta de condições adequadas de trabalho). Ainda, lamentavelmente, tudo indica que este cenário deve piorar nos próximos anos, dada a atual conjuntura econômica, política e social brasileira, que como dito é fortemente desfavorável e tem caminhado para o aprofundamento ainda maior do desmonte das áreas sociais, de educação e de cultura.

Diante disso, temos que nos perguntar: como podemos viver de arte - e com arte - em tempos tão sombrios? Quais as estratégias podemos inventar para resistir num cenário tão adverso? Por que insistir em fazer arte?

Certamente são questões difíceis, para as quais não há uma resposta simples e definitiva. No entanto, se por um lado não encontramos soluções definitivas e exatas, por outro podemos apontar direções para as quais desejamos construir estas respostas. Em outras palavras: é preciso que interroguemos o tempo presente, de forma a atravessá-lo de problematizações que torne possível a invenção de novas estratégias de luta e de existência, que nos coloque em prontidão e disponíveis para a construção de potência.

atividade econômica, queda do PIB até o ponto de recessão, crescente desconfiança dos mercados e do empresariado doméstico (conforme SINGER, 2015).

7 Para um aprofundamento nas análises das crises econômica e política vivenciadas no Brasil nos últimos, ver Jenkings, Dória e Cleto (2016) e Singer (2015). 
Se as condições de existência do artista são profundamente alteradas pelas condições sócio-históricas; se as estruturas e conjunturas políticas, econômicas e sociais participam e afetam diretamente as relações sociais, a organização do mercado e das práticas laborais dos artistas; então poderíamos primeiramente

\begin{abstract}
...investigar como, atualmente, modos específicos de se pensar e viver se massificam, se cristalizam e dificultam, senão impedem, que outras formas de vida aconteçam. Em outras palavras, trata-se de analisar como se fabricam, atualmente, mundos prontos para serem habitados de determinadas formas, ou formas prontas para habitarem determinados mundos, em detrimento de outros (MASCARENHAS, 2018, p. 1541).
\end{abstract}

Nesse sentido, quais são essas formas prontas, esses modos específicos de se ser artista, que assombram os profissionais? Quais os ideais construímos e sustentamos no nosso cotidiano e no nosso imaginário? Por exemplo: o que significa, nos dias atuais, ser artista? E, mais especificamente, o que significa ser artista da cena? Quais as simbologias, imagens e expectativas construímos quando ouvimos alguém dizer que é profissional do teatro ${ }^{8}$ ? 0 que os próprios profissionais esperam alcançar?

Um dos riscos do capitalismo contemporâneo reside em acreditarmos numa "história única" $^{9}$, em nos tornarmos incapazes de construir e reconhecer múltiplas narrativas e possibilidades de existência. Se acreditarmos numa "história única", acreditaremos que há um único jeito, ou certo, ou melhor, de ser artista.

E qual seria este jeito considerado certo, reconhecido socialmente como bem sucedido, de ser artista? Do ponto de vista dos discursos hegemônicos, talvez seja algo como: ser amplamente reconhecido pelas pessoas na ruas (tal qual um ator/atriz de novela da globo); ser muito bem remunerado pelo seu trabalho, e de forma estável; desenvolver um trabalho autoral marcante e inovador, em termos de linguagem/estética; ser admirado pelos seus pares (outros artistas,

8 Por "profissional do teatro" quero designar aquele ou aquela que se dedica à algum dos inúmeros fazeres teatrais, nas mais amplas possibilidades que esta linguagem oferece: seja na atuação, dramaturgia, direção, preparação de elenco, cenografia, trabalho com iluminação, figurino, dublagem, produção, ensino, etc mas também seus entrecruzamentos com outras artes: o cinema, a performance, as artes visuais e multimídia...

90 risco da "história única" é uma crítica e provocação feita pela escritora nigeriana Chimamanda Adichie, em que ela examina as condições de possibilidade e visibilidade de discursos e formas de vida considerados marginais, heterodoxos e menores. Quer dizer: do ponto de vista histórico e epistemológico, há uma série de narrativas, práticas culturais e histórias de vida que são deixadas de lado, em favor de uma "única história": a história (bem sucedida) do patriarcado, do colonialismo, do capitalismo, da branquitude e da heteronormatividade. Todo o resto é ignorado ou exotizado (tratado desde um ponto de vista folclorizado/estereotipado). Para saber mais, ver Adichie, 2009. 
críticos, etc). Todo esse conjunto de prescrições, ainda que possa diferir de artista para artista, é extremamente prejudicial e até mesmo violento, pois além de invisibilizar outras narrativas, pouco a pouco reduz a nossa imaginação, diminui a nossa capacidade de inventar outras formas de se ser artista...

É preciso, então, que consideremos as estruturas sociais que tornam desiguais as oportunidades e a distribuição de recursos - sejam estes simbólicos ou materiais - e que dificultam a emergência de outras narrativas e formas de existência. Nesse sentido, a intelectual indiana Gayatri Spivak destaca o papel da divisão internacional do trabalho na produção e sujeitos subalternos, desprovidos de possibilidades reais de fala:

\begin{abstract}
A divisão internacional do trabalho contemporânea é um deslocamento do campo dividido do imperialismo territorial do século 19. Colocando de forma clara: um grupo de países, geralmente do Primeiro Mundo, está na posição de investir capital; outro grupo, geralmente do Terceiro Mundo, fornece o campo para este investimento, ambos por intermédio de compradores capitalistas nativos e por meio de sua força de trabalho mal protegia e mutável. [...] Devemos agora confrontar a seguinte questão: no outro lado da divisão internacional do trabalho do capital socializado, dentro e fora do circuito da violência epistêmica da lei e educação imperialistas, complementando um texto econômico anterior, pode o subalterno falar? (SPIVAK, 2010, p. 55-67, grifos da autora).
\end{abstract}

Assim, convém nos perguntarmos: o que significa fazer arte em contextos de subalternidade? Quais as especificidades do campo social, político e cultural nos atravessam enquanto produtores artísticos latino americanos em geral, mas particularmente enquanto artistas negros, LGBTQI's, indígenas, periféricos? É fundamental que consideremos esses cortes na experiência de cada um, evitando leituras essencialistas e generalistas do que é ser artista. Produzir e viver de arte implica em escolhas e condições muito distintas em cada caso, e é necessário que explicitemos esses lugares de produção e de fala. Ainda, é importante que façamos a crítica aos ideais, sejam eles quais forem. Desenvolver uma poética que esteja referenciada nas condições concretas do presente, e não na idealização do fazer artístico.

\title{
Segundo Ato: movimentações de cena (experimentações e exercícios de expansão)
}


Se é verdade que as forças biopolíticas ${ }^{10}$ ganham terreno no campo social, também é verdade que as formas de resistência (e existência) se multiplicam. Viver de outras maneiras se tornou algo não apenas desejável, mas profundamente necessário. Não seria exagero dizer que atingimos um limite: contra o estrangulamento e rebaixamento da vida, nos opomos fazendo arte!

As estratégias de resistência, atualmente, passam por uma série de aspectos - passam por, não se resumem à.

Passam por revermos nossas formas de consumo cotidiano e nosso estilo de vida. Em fazermos a crítica das formas capitalísticas de existência. Passam pelo desapego ao luxo e ao conforto exacerbado, em fazer o elogio à vida interessante, e não à vida segura; passam por aprendermos a gozar diferentemente no mundo material. Passam por desenvolvermos nossa resiliência, por aprendermos a lidar com a instabilidade financeira, por aprendermos a passar pelas épocas de escassez, por aprendermos a ganhar dinheiro de diferentes formas e a não sofrermos demasiado com esse permanente estado de insegurança e precarização do trabalho. Porque, inclusive estas são questões que ultrapassam o contexto das artes, e alcançam todos os sujeitos no mundo do trabalho contemporâneo:

O trabalho se desprendeu de lugares, tempos e conteúdos específicos e se transformou em uma categoria abstrata. Contudo, essa abstração do trabalho e do nosso compromisso para com ele é algo real e concreto: "trabalho abstrato" tornou-se uma categoria empírica, experiencial. A experiência da abstração do trabalho (o deslocamento em relação à sua concretude) se expressa, por exemplo, na perda de confiança em relação à permanência no emprego ou mesmo com relação à estabilidade da comunidade próxima. Ocorrem mudanças repentinas e deslocamentos em nossas profissões e áreas de trabalho, e temos de nos mover de tarefa em tarefa, de projeto em projeto. Lugares e tempos de trabalho variam, e mais importante do que aprender algo ligado a um conteúdo específico é hoje "aprender a aprender". Assim, como em qualquer empresa, preciso acompanhar o que acontece à minha volta ao mesmo tempo em que devo evitar uma relação excessiva ou profunda com as coisas que faço ou as pessoas que encontro. O compromisso é um risco, e pode levar ao fracasso pessoal quando as opções precisam ser deixadas em aberto em meio à multiplicidade de possibilidades imprevisíveis. De maneira que é preciso ter um interesse oportunista em relação a tudo, e ao mesmo tempo é preciso, cinicamente, não ter interesse em nada, sendo mais prudente manter-se um pouco distante e entediado (VIRTANEN, 2011, p. 56).

10 Trata-se de um termo cunhado por Michel Foucault para designar o conjunto de práticas de controle ampliado e irrestrito da vida e de gestão das populações, baseadas nas disciplinas (adestramento do corpo, organização e extração de suas forças e utilidades) e controles (vigilância constante e difusa, autocontrole, etc). Há uma correspondência muito forte entre a noção de biopolítica e os ideais dos quais falávamos, posto que ambos são linhas de força que inscrevem relações de saber e poder que influenciam nossos modos de viver e pensar. Para saber mais, ver Foucault (1979 e 2008). 
Mas como lidar com esse cenário tão perverso? Certamente, não há um modo fácil ou definitivo de fazê-lo. No entanto, lembremos sempre que o artista tem a linguagem da arte como arma. De tal modo que isso significa fazermos da arte o veículo de superação dessa condição precária; onde o mercado quer nos impor o medo, a instabilidade, o individualismo, podemos opor, artística e eticamente, o gozo, a alegria, os rituais de celebração da vida, a grupalidade e o bando como modo de existência...

Resistir passa também pela insistência. Insistir, sustentar a tensão, aquela que se dá na criação: "criar, apesar de" - porque, agora mais do que nunca, precisaremos construir inúmeras linhas de fuga, inúmeros "apesar de". Resistir e fazer arte nos dias atuais significa, mais uma vez, ir em frente, a despeito de todas as adversidades, contra tudo e contra todos. Mais do que isso, "criar um teatro de urgência", que nos viabilize no mundo e denuncie todas as obscuridades do tempo presente.

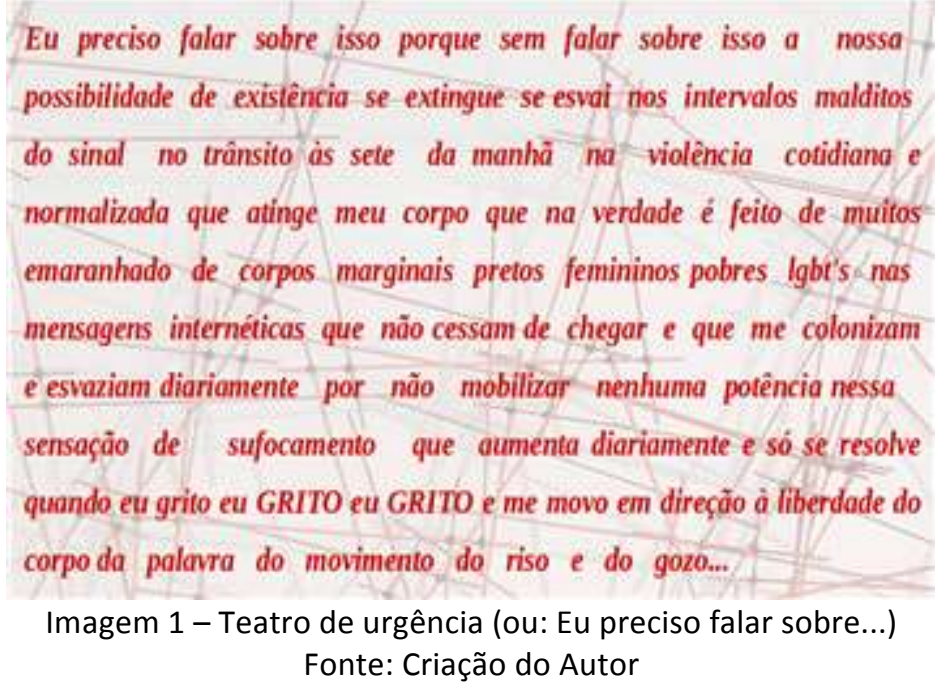

Resistir, atualmente, passa também pelo aquilombamento, e suas múltiplas possibilidades de acoplamento e composição. Por um lado, o aquilombamento em si guarda e intensifica a potência e a resistência dos corpos negros, colocando a questão racial em primeiro plano, e o faz evocando uma atualização das lutas e identidades negras, num processo que envolve um entrelaçamento contínuo entre passado, presente e futuro, o reconhecimento das ancestralidades que atualizam e constituem os corpos negros, e que aumentam a capacidade de ativar a imaginação de novos futuros. Por outro lado, o aquilombamento também pode inspirar outras 
grupalidades: trata-se de identificar e estar com os nossos, viver e resistir em bando, em produzir bons encontros, à lá Espinosa, encontros alegres, que nos potencializam de modo a ampliar nossa capacidade de agir sobre o mundo. Encontrar nossos parceiros, estar com eles, produzir com eles, refugiarmo-nos neles: e, claro, fazer isso incorporando as pautas e vetores políticos que dão visibilidade aos modos marginais de existência - empretecer a existência, atravessá-la de devires LGTBQI+, feministas, anarquistas, loucos, festivos, construídos na diferença....

Resistir passa também por um exercício de descentralização: não é a arte autoral do artista que deve estar em foco, mas a arte em si, de forma expandida. Fazer arte no mundo de hoje, em contextos de subalternidade, na melhor das hipóteses, significa conciliar trabalho autoral com outras formas de fazer artístico: dar aulas, realizar oficinas e workshops, desenvolver projetos paralelos (inclusive projetos comerciais que podem não ter nenhuma relação com suas pretensões estéticas), escrever projetos, explorar os múltiplos lugares que a arte pode lhe oferecer (no campo do teatro: praticar-experimentar a dramaturgia, iluminação, atuação produção, direção, cenografia, etc., mas também ultrapassar as fronteiras do próprio teatro, inventando composições transdisciplinares, incitando a contaminação do teatro por outras linguagens - a dança, a performance, as artes visuais, a literatura, o cinema, as ciências sociais, a filosofia...). Trata-se, em outras palavras, de construir para si um arranjo que torne possível e viável a vida como artista, que nos possibilite realizar nossos projetos autorais e ao mesmo tempo sobreviver diante das exigências da vida social.

Este arranjo tende a ser tanto melhor quanto mais composto por atividades de natureza artística. Em vez de "conciliar" o fazer artístico com atividades de outra natureza (por exemplo, ter um emprego administrativo num outro setor produtivo), procurar envolver-se com outras atividades artísticas que gerem alguma renda. Não se trata aqui de julgar desde um ponto de vista moral o trabalho em outros setores, mas de fortalecermos a nossa capacidade de resistir dentro de um domínio que é o da profissionalização artística. Nesse sentido, dedicar-se à outras atividades artísticas não apenas fortalece o setor, mas o próprio fazer dos artistas, na medida em que isso nos ajuda a manter um constante processo de aprendizado, descobrindo novas possibilidades estéticas e novas formas de produção.

Este arranjo artístico vai de encontro à noção de "artista-etc." de Ricardo Basbaum:

Quando um artista é artista em tempo integral, nós o chamaremos de 'artista-artista'; quando o artista questiona a natureza e a função de seu papel como artista, escreveremos 
'artista-etc.' (de modo que poderemos imaginar diversas categorias: artista-curador, artista-escritor, artista-ativista, artista-produtor, artista-agenciador, artista-teórico, artista-terapeuta, artista-professor, artista-químico etc.); [...] Vejo o 'artista-etc.' como um desenvolvimento e extensão do 'artista-multimídia' que emergiu em meados dos anos 1970, combinando o 'artista-intermídia' fluxus com o 'artista-conceitual' - hoje, a maioria dos artistas (digo, aqueles interessantes) poderia ser considerada como 'artistasmultimídia', embora, por 'razões de discurso', estes sejam referidos somente como 'artistas' pela mídia e literatura especializadas. 'Artista' é um termo cujo sentido se sobrecompõe em múltiplas camadas (o mesmo se passa com 'arte' e demais palavras relacionadas, tais como 'pintura', 'desenho', 'objeto'), isto é, ainda que seja escrito sempre da mesma maneira, possui diversos significados ao mesmo tempo. Sua multiplicidade, entretanto, é invariavelmente reduzida apenas a um sentido dominante e único (com a óbvia colaboração de uma maioria de leitores conformados e conformistas). Logo, é sempre necessário operar distinções de vocabulário. O 'artista-etc.' traz ainda para o primeiro plano conexões entre arte\&vida (o 'an-artista' de Kaprow) e arte\&comunidades, abrindo caminho para a rica e curiosa mistura entre singularidade e acaso, diferenças culturais e sociais, e o pensamento. [...] Amo os artistas-etc. Talvez porque me considere um deles, e não é correto odiar a mim mesmo (BASBAUM, 2005).

E, finalmente, podemos dizer que resistir, e existir na diferença, passa também por fortalecermos e reinventarmos nossas redes produtivas: criar novos circuitos e novas formas de viabilização (e visibilidade) do nosso trabalho artístico, inventar novos espaços para práticas de pesquisa, intercâmbio de experiências, ideias e aprendizados, e também novos modos de vender a capitalizar nosso trabalho (por exemplo, explorar de modo intensivo e estratégico as redes virtuais, reinventar o circuito de festivais e feiras artísticas, buscando novos meios de financiá-los, etc).

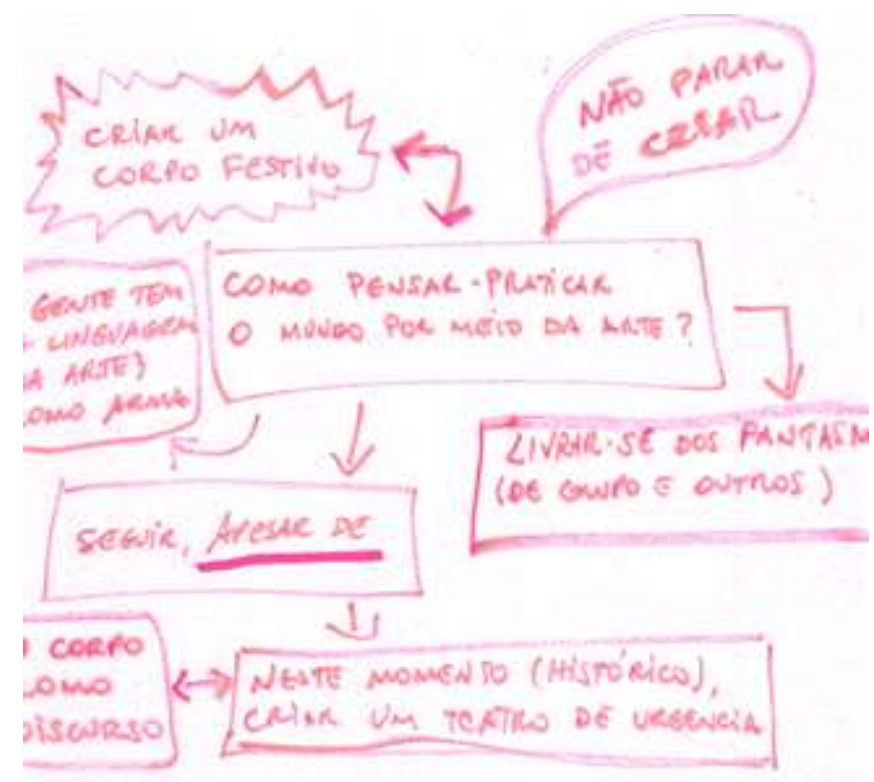

Imagem 2 - Experimentar o mundo por meio da arte Fonte: Criação do autor. 


\title{
Último ato: como terminar uma reflexão que não possui fim?
}

\begin{abstract}
Àquelas de nós cuja existência social é matizada pelo terror; àquelas de nós para quem a paz nunca foi uma opção; àquelas de nós que fomos feitas entre apocalipses, filhas do fim do mundo, herdeiras malditas de uma guerra forjada contra e à revelia de nós; àquelas de nós cujas dores confluem como rios a esconder-se na terra; àquelas de nós que olhamos de perto a rachadura do mundo, e que nos recusamos a existir como se ele não tivesse quebrado: eles virão para nos matar, porque não sabem que somos imorríveis. Não sabem que nossas vidas impossíveis se manifestam umas nas outras. Sim, eles nos despedaçarão, porque não sabem que, uma vez aos pedaços, nós nos espalharemos. Não como povo, mas como peste: no cerne mesmo do mundo, e contra ele (MOMBAÇA, 2017, s/p.).
\end{abstract}

Se temos a linguagem como arma (e sabemos muito bem o quão perigosa e poderosa ela é: basta ver todo o temor que ela provoca, e como os poderes instituídos se investem contra ela com tanta obstinação); se criar é para nós uma necessidade vital, sem a qual não vivemos; se lembrarmos que os governos - por mais atrozes que sejam - passam; se compreendermos e aceitarmos a transitoriedade e processualidade da vida - que não há estados definitivos, lugares de chegada, situações ideais; se conseguirmos fazer da vida arte, e da arte vida; então não temos nada a temer.

\section{Referências}

ADICHIE, Chimamanda. The danger of a single story [vídeo, 18 min.]. TED: Ideas worth spreading. Publicado em 28 julho de 2009. Disponível em: <https://www.ted.com/talks/chimamanda_adichie_the_danger_of_a_single_story>. Acesso em 2 ago. 2019.

BASBAUM, Ricardo. Amo os artistas-etc. In: MOURA, Rodrigo. Políticas institucionais, práticas curatoriais. Belo Horizonte: Museu de Arte da Pampulha, 2005. 80 p.

DELEUZE, Gilles. Conversações. São Paulo: Editora 34, 1992.

FOUCALT, Michel. Microfísica do Poder. Rio de Janeiro: Graal, 1979.

Segurança, Território, População: curso no Collège de France (1977-1978). São Paulo: Martins Fontes, 2008.

. Vigiar e punir: nascimento da prisão. 27. ed. Petrópolis: Vozes, 2003. 262 p.

JENKINGS, Ivana; DORIA, Kim; CLETO, Murilo (orgs). Por que gritamos golpe? Para entender o impeachment e a crise política no Brasil. São Paulo: Boitempo, 2016. 
MASCARENHAS, Leonardo Balbino. Biopolítica, Educação e Resistência na Contemporaneidade. Educação \& Realidade. Porto Alegre, v. 43, n. 4, p. 1537-1554. out. 2018. Disponível em: <http://www.scielo.br/scielo.php?script=sci_arttext\&pid=S217562362018000401537\&lng=en\&nrm=iso>. Acesso em: 2 ago. 2019.

MOMBAÇA, Jota. O mundo é meu trauma. Piseagrama. Belo Horizonte, número 11, pág. 20-25, 2017. Disponível em: <https://piseagrama.org/o-mundo-e-meu-trauma/>. Acesso em 2 ago. 2019.

SANTOS, Boaventura de Sousa. A globalização e as ciências sociais. 2. ed. São Paulo: Cortez, 2002. $572 p$

SANTOS, Boaventura de Sousa; MENESES, Maria Paula. Epistemologias do Sul. Coimbra: CES/Almedina, 2010.

SINGER, André. Cutucando onças com varas curtas: o ensaio desenvolvimentista no primeiro mandato de Dilma Rousseff (2011-2014). Novos Estudos, v. 102, p. 39-67, jul. 2015.

SPIVAK, Gayatri Chakravorty. Pode o subalterno falar? Belo Horizonte: Editora UFMG, 2010.

VIRTANEN, Akseli. O discreto charme do precariado (posfácio). In: GUATTARI, Félix. Máquina Kafka | Kafkamachine. (edição bilingue). São Paulo: n-1 edições, 2011.

Artigo submetido em 02/08/2019, e aceito em 13/12/2019. 